\title{
Molekulare Mechanismen näher untersucht
}

Morbus Bechterew führt zu langwierigen und schmerzhaften Entzündungen der Gelenke und letztlich zu einer Verformung der Wirbelsäule. Das HLA-B27-Protein könnte eine Ursache der Erkrankung sein.

Proteine falten sich nach ihrer Herstellung in eine dreidimensionale Struktur. Das HLA-B27-Protein, welches die meisten Patienten mit Morbus Bechterew in ihren Zellen aufweisen, könnte durch seine besonders langsame und komplizierte Faltungsweise die Krankheit auslöst.

Forscher der Jacobs University in Bremen haben in Zusammenarbeit mit Kollegen der Freien Universität Berlin herausgefunden, wie diese Faltung und die anschließende Qualitätskontrolle des HLA-B27-Proteins genau ablaufen. Dr. Zeynep Hein, Postdoc in der Forschungsgruppe von Prof. Dr. Sebastian Springer an der Jacobs University, hat dazu den Transport des HLA-B27-Proteins innerhalb von menschlichen Zellen genau untersucht [1].

Dazu wird eine gentechnisch stabilisierte Form des HLA-B27-Proteins hergestellt und mit dem in unserem Körper vorkommenden Protein verglichen. „Wir haben uns schon immer für den Transport von Proteinen in Zellen interessiert und sind geübt darin, künstliche Proteine herzustellen um den Transportvorgang so zu untersuchen", so Hein. Die Experimente werden in Zellkultur, also nicht unter Beteiligung von Patienten, durchgeführt.

Unter anderem konnten Hein und ihr Team herausfinden, dass das HLA-
B27-Protein sich nur sehr schwer in seine spezielle Struktur falten kann. Und selbst wenn es sich falten kann, neigt das Protein dazu, gleich wieder zu zerfallen und dadurch seine Funktion zu verlieren.

Literatur

1. Hein Z, Borchert B, Abualrous ET, Springer $S$ (2018) Distinct mechanisms survey the structural integrity of HLA-B*27:05 intracellularly and at the surface. PLOS ONE. https:// doi.org/10.1371/journal.pone.0200811

rheuma plus $2019 \cdot 18: 89$

https://doi.org/10.1007/s12688019-0249-8

(C) Springer-Verlag GmbH Austria, ein Teil von Springer Nature 2019
Quelle: Presseaussendung der Jacobs University Bremen

Hier steht eine Anzeige. 